FULL RESEARCH ARTICLE

\title{
Owens Valley nesting willow flycatcher under pressure
}

\section{LACEY GREENE $^{1 *}$, ELSBETH OTTO ${ }^{1}$, AND CHRIS MCCREEDY $^{2}$}

${ }^{1}$ California Department of Fish and Wildlife, Region 6, 787 North Main Street, Bishop, CA 93514, USA

${ }^{2}$ Atwell, LLC, 2 Towne Square \#700, Southfield, MI 48076, USA

*Corresponding Author: lacey.greene@wildlife.ca.gov

Willow flycatchers (Empidonax traillii; WIFL) nest along the Owens River and Horton Creek in the Owens Valley. Migrating WIFL visit these sites as well as many other tributaries to both the Owens River and Mono Lake. We estimate there are approximately 35 WIFL territories in the Owens valley, or 5\% of territories in California. Nesting WIFL in the Owens Valley are likely the federally endangered southwestern subspecies (E. $t$. extimus; SWIFL). The Chalk Bluff nesting site is particularly important as large nesting areas tend to be both rare and important for SWIFL and it contains more than half $(63 \%)$ of all known WIFL territories in the region, which also represents $12 \%$ of all nesting SWIFL in California. Between 2014 and 2016, WIFL territory numbers declined from 37 to 27 across the three largest breeding sites. Territory numbers may have been influenced by drought conditions or brown-headed cowbird (Molothrus ater; BHCO) nest parasitism. In 2015 and 2016, comprehensive nest monitoring found nest parasitism rates were $>40 \%$, and nest success was lower in parasitized nests $(16 \% ; \mathrm{N}=5 / 31)$ compared with non-parasitized nests $(60 \% ; \mathrm{N}=31 / 52)$. BHCO management could potentially improve nest success for WIFL as well as many other open-cup nesting riparian birds in the Owens Valley.

Key words: brown-headed cowbird, callback surveys, Empidonax trailii, Empidonax trailii extimus, Molothrus ater, nest parasitism, nest success, Owens River, riparian birds, southwestern willow flycatcher, willow flycatcher

Willow flycatchers (Empidonax traillii; WIFL) are a riparian obligate passerine that associate with both riverine and meadow habitat. Within California, all WIFL subspecies were classified as endangered in 1991 and protected under the California Endangered Species Act (CESA), and in 1995, SWIFL was specifically identified as endangered and protected under the Federal Endangered Species Act (U.S. Fish and Wildlife Service [USFWS] 2002). Although the southwestern subspecies designation has been supported by genetic, morphometric, and behavioral analyses, it is not possible to separate willow flycatcher 
subspecies from visual observations. All three subspecies (E. t. extimus, E. t. adastus, and E. t. brewerii) may be encountered within Inyo and Mono counties during migration, and the boundary between the breeding distributions of E. t. extimus and E. t. adastus is not well-defined (Theimer et al. 2016). Here, we refer to territorial birds within the USFWS designated SWIFL critical habitat (Fig. 3 in USFWS 2002, 2013) as E. t. extimus (SWIFL), but otherwise do not specify a subspecies designation (WIFL).

In the last 30 years, WIFL breeding sites declined by $50 \%$ in the Sierra Nevada region of California (Loffland et al. 2014), including complete extirpation from Yosemite National Park (Siegel et al. 2008). Additionally, breeding populations have rapidly declined at two breeding sites for federally endangered SWIFL within California: along the Kern River (M. Whitfield, Southern Sierra Research Station, personal communication) and at Pendleton Marine Corps Base, which once held the second-largest breeding population of the subspecies in the state (Kus et al. 2017). These declines have been driven by habitat loss and degradation, BHCO nest parasitism (Fig. 1), and livestock grazing (USFWS 2002). Declines may be further exacerbated by the changing climate (Ruegg et al. 2018).

SWIFL nesting in the Owens Valley were first formally documented in 1944 (Grinnell and Miller 1944). In 1993, canoe surveys confirmed nesting SWIFL along the Owens River between Pleasant Valley Reservoir and Bishop (Laymon and Williams 1994). Between 2001 and 2006, 5 sites and 28 territories were identified in the Owens Valley (Durst et al. 2007; Rourke et al. 2004). Additionally, a small, breeding WIFL population existed near Mono Lake from 2000-2012, but the subspecies was not determined (McCreedy and Heath 2004).

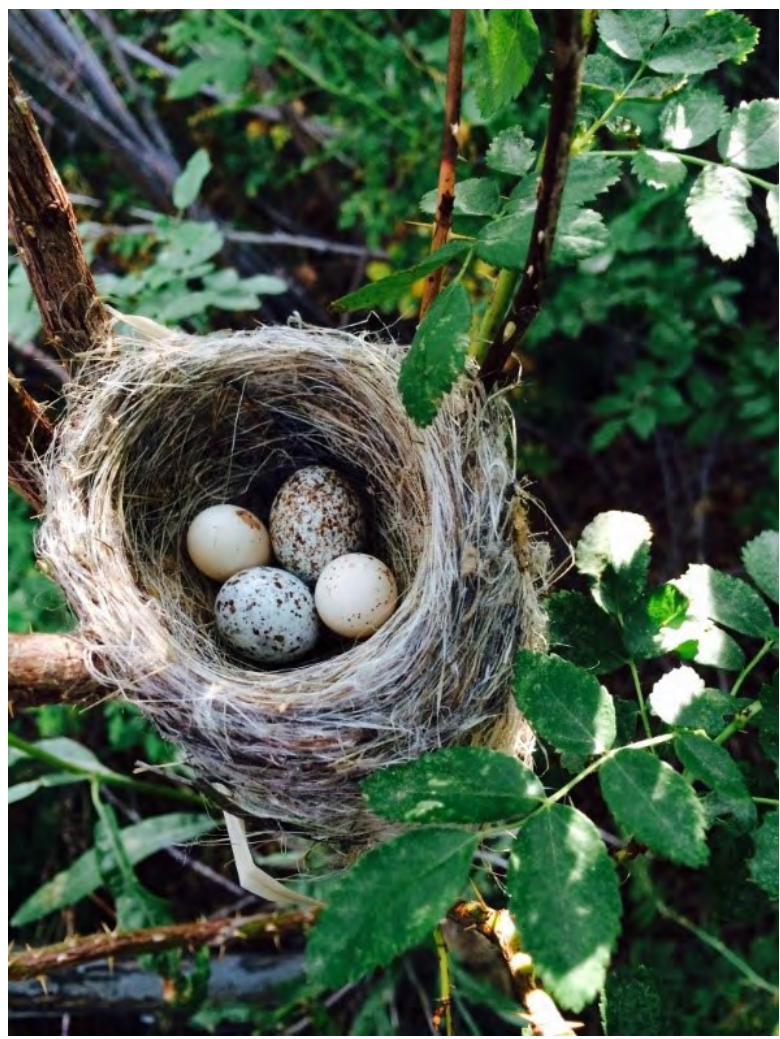

Figure 1. Parasitized southwestern willow flycatcher nest with two brown-headed cowbird eggs (larger). Photo Credit: Dave Bell. 
The Los Angeles Department of Water and Power (LADWP) identified SWIFL as a target species in their conservation planning for Inyo and Mono counties. The City of Los Angeles (LA) owns the majority of lower-elevation riparian habitat in Inyo and Mono counties including 125,450 ha (310,000 acres) of land, on which exist $724 \mathrm{~km}$ (450 mi) of natural waterways, $178 \mathrm{~km}$ (111 mi) of man-made waterways (ditches and canals), and $135 \mathrm{~km}$ (84 mi) of aqueducts. This land is managed by LADWP primarily for water gathering but also for power production. We implemented surveys to provide updated and more comprehensive information on the current distribution and abundance of WIFL in Inyo and Mono counties. We also implemented nest monitoring to determine if BHCO parasitism (Fig. 1) might be impacting the species in this region.

\section{METHODS}

\section{Study Area}

We surveyed all WIFL riparian habitat between $1120-2440 \mathrm{~m}$ with slope $<20^{\circ}$ in Inyo and Mono counties. WIFL use this habitat from May to August (Fig. 2), when conditions are hot and dry, although micro-habitat within riparian areas is often cooler and moister than in surrounding upland. This land was predominantly owned by LA, but also included some areas owned privately or by the U.S. Forest Service, Paiute Tribe, or California State Parks. From May to August, the average high temperature in Bishop, California is $33.3^{\circ} \mathrm{C}$ with an average of $0.4 \mathrm{~cm}$ of precipitation per month. Habitat includes both diverse, multi-tiered riparian vegetation and near-monocultures of similar height. More complex habitat typically includes coyote willow (Salex exigua) and wild rose (Rosa woodsii) with red willow ( $S$. laevigata) or Fremont's cottonwood (Populus fremontii) overstory. Non-native salt cedar (Tamarix ramosissima) and Russian olive (Elaeagnus angustifolia) are also present, but generally rare. Additionally, along the Owens River, there are long stretches that are nearmonocultures of coyote willow and a few monoculture sections of salt cedar, particularly just north of Tinnemaha Reservoir. Higher-elevation tributaries with steeper gradients are dominated by water birch (Betula occidentalis). In addition to WIFL and BHCO, common riparian birds include Bewick's wren (Thyromanes bewickii), bushtit (Psaltriparus minimus), red-winged blackbird (Agelaius phoeniceus), song sparrow (Melospiza melodia), and yellow warbler (Setophaga petechia). Observed mammals within the area include beaver (Castor candadensis) and mink (Neovison vison).

\section{Study Design}

We assessed the distribution and abundance of WIFL within the Owens Valley and Mono Basin below 2440 m using standardized callback surveys (Sogge and Sferra 2010). This included 36 sites (195 km of survey tracks) in 2014 and 36 sites (124 km of survey tracks) in 2015 of riparian habitat. A subset of nesting sites were also revisited in 2016 for further nest monitoring (Laue 2017). Most nesting SWIFL were associated with the Owens River and within USFWS designated critical habitat for the southwestern subspecies (Fig. 2).

We identified survey sites using a habitat suitability model that incorporated the presence of water, canopy closure, percent willow, habitat width, habitat patch size, and elevation (developed by S. Laymon for LADWP, unpublished). A few sites identified in the model were later excluded when field visits revealed they did not contain adequate habitat 


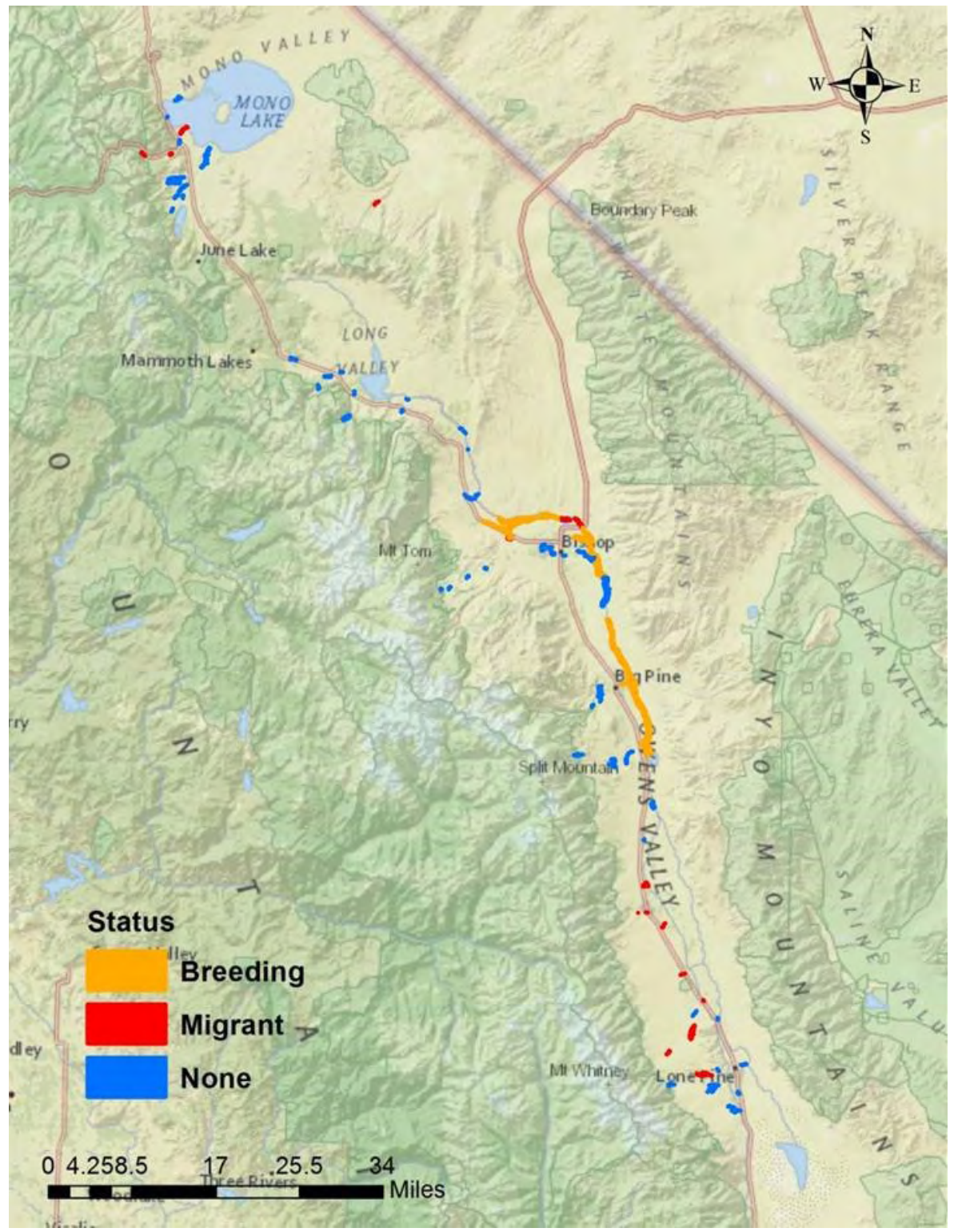

Figure 2. Distribution of willow flycatcher based on 2014-2015 callback surveys in the Owens Valley and Mono Basin, CA, USA. Breeding birds were identified by their presence throughout the breeding season.

and a few sites were added based on local knowledge and desktop review $(<5 \%)$. We classified sections of the Owens River as separate sites based on natural breaks in vegetation or by road crossings. Site size and complexity were variable; survey timing of individual sites ranged from $<30$ minutes to 80 hours per visit (visits occasionally involved multiple surveyors and multiple days). 
Each site was visited at least three times between 14 May and 31 July (Sogge and Sferra 2010) either by foot, canoe, or both for wider habitat. As needed, survey timing was shifted up to 7 days from protocol-specified time periods, based on bird arrival and activity, weather, and staff capacity. Surveyors initially listened for WIFL for 1-2 minutes, and if not heard, broadcast 10-15 seconds of WIFL song recordings ("fitzbews" and "britts") from handheld speakers with consistent amplification matching surround bird noise, from within WIFL habitat (Sogge and Sferra 2010). Listening and broadcasting were repeated every 30 meters throughout site. WIFL presence was confirmed by a "fitzbew" and also occasionally confirmed by observing silent or "whit-ting" birds based on observation details and observer experience. WIFL were also confirmed from opportunistic observations unassociated with specific survey efforts.

Repeated observations from five breeding sites indicated that we were consistently able to identify the presence of breeding birds throughout the survey season. Therefore, we considered WIFL to be migrants if they were 1) observed only during a single visit OR 2) observed in the first survey window and then only again late in the third survey window, assuming this could represent separate spring and fall migration events. Within active breeding sites, it was not always possible to distinguish migrants from residents.

We conducted territory mapping (2014-2016) and nest monitoring (2015-2016; following Martin and Geupel 1993) at the three largest nesting sites, which included over 85\% of the known breeding territories in the region. Territories were determined by the presence of an active nest or the persistent presence of birds in the breeding period. With careful and repeated behavioral observations ("whit-ting", counter "whit-ting", interactions, and sometimes nests), territories were identified as having a single male, pair, or polygynous groups ( 2 females, 1 male). Typically SWIFL will remain within a territory during a season, although some single males may move territories mid-season (Sogge and Sferra 2010). To avoid double counting, areas in which birds were observed ONLY prior to June 22 or ONLY after July 11 were not counted as territories unless there was an active nest.

Nest monitoring effort and survey area extent varied between years, with an initial trial in 2014 toward the end of the callback survey season and more consistent effort at the three largest nest sites (Chalk Bluff, Horton, S. Hwy 6) in 2015 and 2016. A nest was considered active only if a SWIFL egg or nestling was observed; partially built nests or nests that were only observed holding $\mathrm{BHCO}$ eggs or young were not considered active. Nests were considered parasitized if they either A) had a BHCO egg or nestling OR B) had damaged but uneaten SWIFL eggs or a SWIFL nestling on the ground, even if no BHCO was observed the in nest. Successful nests fledged at least one SWIFL. Typically fledglings were observed, but occasionally fledging was assumed if a nestling $>10$ days old (Paxton and Owen 2002) was observed and the nest was found undisturbed after that time. If at least one fledgling was observed and there were no other signs of disturbance, we assumed all nestlings fledged. In 2015 and 2016, nests were monitored every 3-7 days to determine nest fate. We did not approach nests in the presence of BHCO to avoid increasing the risk of nest parasitism or predation.

\section{RESULTS}

WIFL were present in one quarter of all sites, including 36\% of Mono Basin sites, $0 \%$ of Long Valley sites (between Owens River headwater and Crowley reservoir), and 24\% of Owens Basin sites (Fig. 2). WIFL were often detected only within in a small portion of each 
site, indicating there was often variable habitat quality within sites. All WIFL observations occurred in habitat dominated by native plant species, although some non-native species were occasionally present (both salt cedar and Russian olive). Migrants occupied more locations and more varied habitat than breeding birds, including smaller habitat patches and lower-order waterways in steeper terrain with faster-moving water. Migrants were observed using the same survey sites where SWIFL nesting territories were also located. However, because birds were not banded, it was not always possible to distinguish migrants from residents and identify the numbers of migrants in nesting areas.

Breeding SWIFL were found along the Owens River and nearby along one of its tributaries, Horton Creek (Fig. 2 and Table 1). In the overall region we estimate there are $\sim 35$ territories with the majority ( $63 \%)$ of territories within the Chalk Bluff Site (Table 1). We did not find any nesting SWIFL along the Owens River between highway 6 and 5 Bridges Road, where they had previously been documented in 2001 (Rourke et al. 2004). In 2014, we did find a single "whit-ting" bird at this site during an early visit, but with no further observations during subsequent visits, we did not consider this a territory. We also did not find nesting SWIFL along Rush Creek near Mono Lake, where females had previously been documented from 2001-2011 (C. McCreedy, personal communication). Before these surveys, Horton Creek was not previously identified in the literature as a SWIFL nesting site.

Only the Chalk Bluff site consistently had $>5$ SWIFL territories (Table 1). With an average of 22 territories, the Chalk Bluff site has half of all known territories within the Basin and Mojave Recovery Unit for SWIFL (Durst et al. 2008). Most territories (31/38; $83 \%$ ) found in 2015 were in the same location as territories documented in 2014, although without individually marked birds, it was not possible to determine individual site and territory fidelity. Of the 106 territories identified, most $(85 \%)$ were in pairs of 1 female and 1 male while $9 \%$ were single males and $6 \%$ were polygynous groups with 2 females.

We identified the fate of 85 active SWIFL nests (Table 2). Overall nest success was $45 \%(\mathrm{~N}=38)$, but it varied between years and sites (Table 2). The earliest first SWIFL egg was detected on 9 June, the latest was detected on 22 July, and the average date of laying the first egg was 26 June; the earliest hatch day was 23 June, the latest was 2 August, and the average was $11 \mathrm{July}$; the earliest fledgling was observed on 4 July, the latest on 16 August, and the average date of fledging was 27 July. Averages were calculated only using data from 2015 and 2016, when there was comprehensive nest monitoring throughout the breeding season.

For all active nests with known outcome, the nest parasitism rate was $37 \%$ (range 18-43\%) between 2014 and 2016 (Table 2). The lower parasitism rate in 2014 was likely influenced by late and incomplete nest monitoring that year. BHCO were observed in all nest sites and parasitism was documented in all nest sites except for the Owens River South of Line Street. However, there was only a single nest with known fate at this site. At sites with $\geq 5$ nests monitored, BHCO parasitism ranged from 33 to $67 \%$. In addition, we documented 21 SWIFL nests that we did not consider active (no SWIFL eggs observed), that were abandoned with a BHCO egg. Typically, SWIFL seemed to abandon inactive parasitized nests shortly after BHCO eggs were laid, but one inactive nest did support a BHCO to the nestling phase before the nestling was later found dead in the nest. Parasitized nests had lower nest success $(16 \% ; \mathrm{N}=5 / 31)$ than non-parasitized nests $(60 \% ; \mathrm{N}=31 / 52$; Pearson's $\chi^{2}=13.236, \mathrm{df}=1, \mathrm{P}<0.001 ;$ Table 2$)$. 
Table 1. Results from territory and nest monitoring from all known nesting sites for southwestern willow flycatcher in the Owens Valley, CA, USA, 2014-2016. Includes nests at all stages of development.

\begin{tabular}{|c|c|c|c|c|c|c|c|c|c|c|c|c|}
\hline \multirow[b]{2}{*}{ Site } & \multicolumn{3}{|c|}{2014} & \multicolumn{3}{|c|}{2015} & \multicolumn{3}{|c|}{2016} & \multicolumn{3}{|c|}{ 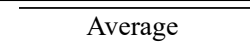 } \\
\hline & $\mathrm{N}$ & Territory & Nest* & $\mathrm{N}$ & Territory & Nest & $\mathrm{N}$ & Territory & Nest & $\mathrm{N}$ & Territory & Nest \\
\hline Horton & 9 & 5 & (0) & 11 & 5 & 9 & 8 & 4 & 9 & 9.3 & 4.7 & 9.0 \\
\hline Chalk Bluff & 45 & 24 & (16) & 43 & 22 & 38 & 37 & 20 & 25 & 41.7 & 22.0 & 31.5 \\
\hline S Hwy 6 & 13 & 8 & (4) & 12 & 6 & 10 & 6 & 3 & 5 & 10.3 & 5.7 & 7.5 \\
\hline S Line & 4 & 2 & 1 & 3 & 2 & 0 & NS & NS & NS & 3.5 & 2.0 & 0.5 \\
\hline Big Pine & 2 & 1 & 1 & 2 & 1 & 1 & NS & NS & NS & 2.0 & 1.0 & 1.0 \\
\hline Tinnemaha & 2 & 1 & 1 & 4 & 2 & NS & NS & NS & NS & 3.0 & 1.5 & 1.0 \\
\hline Totals & 75 & 41 & 23 & 75 & 38 & 58 & 51 & 27 & 39 & 67 & 35 & 50 \\
\hline
\end{tabular}

$\mathrm{NS}=$ not surveyed.

*Reduced nest search effort in 2014 (not included in averages)

Table 2. Results from southwestern willow flycatcher nest monitoring in the Owens Valley, CA, USA, 2014-2016 from all active nests (SWIFL egg present) with known fate. Percentages reported because nest search effort and area covered was not consistent between years.

\begin{tabular}{lccccc}
\hline Year & $\begin{array}{c}\text { Nests with } \\
\text { Known } \\
\text { Outcome }\end{array}$ & $\begin{array}{c}\text { Nest } \\
\text { Success } \\
(\%)\end{array}$ & $\begin{array}{c}\text { Nest } \\
\text { Parasitism } \\
\text { Rate }(\%)^{*}\end{array}$ & $\begin{array}{c}\text { Non-para- } \\
\text { sitized Nest } \\
\text { Success }(\%)^{*}\end{array}$ & $\begin{array}{c}\text { Parasitized } \\
\text { Nest Success } \\
(\%)^{*}\end{array}$ \\
\hline $2014^{\mathrm{a}}$ & 17 & 65 & 18 & 71 & 33 \\
2015 & 40 & 45 & 42 & 64 & 13 \\
2016 & 28 & 32 & 43 & 44 & 17 \\
All Nests $^{\mathrm{b}}$ & 85 & 45 & 37 & 60 & 16 \\
\hline
\end{tabular}

*Does not include 2 nests in 2015 for which parasitism status was not determined.

a 2014 nest monitoring began in the middle of the nesting season.

${ }^{\mathrm{b}}$ Calculated from all data combined, not average across years.

\section{DISCUSSION}

Although once a common bird in California (Unitt 1987), WIFL abundance and distribution have declined since 1970, and the current estimate is that there are 650 territories in the state (Schofield et al. 2021). Recent conservation efforts, particularly those targeting habitat restoration and $\mathrm{BHCO}$ management, have had mixed results and highlight the importance of local knowledge for effective management (USFWS 2002; Rourke et al. 2004; Schofield et al. 2021). We assessed the current distribution and abundance of WIFL in Inyo and Mono counties to inform management and performed nest monitoring to elucidate relevant local threats, particularly BHCO nest parasitism. 
Due to the thorough geographic extent of our surveys, these results likely represent a census of SWIFL nesting sites within the Owens Valley and Mono Basin. Cooperation from many landowners (California State Parks, USFS, Bishop Paiute Tribe, private entities and most importantly, LADWP) enabled us to survey all WIFL habitat in the region. All nest sites, as well as most potential habitat in the region, are located on land owned by LA and managed by LADWP. In general, we found more nesting sites and more territories than previous surveys (Laymon and Williams 1994; Rourke et al. 2004). However this does not necessarily represent an increase in the overall population as past efforts were not as comprehensive, often covering smaller areas, including fewer visits per site, or surveying only by canoe or foot, instead of both. Our migratory WIFL observations do not likely represent a census of sites used by migratory birds because migrants may spend a short time at a site and the survey protocol is not intended to locate all migrants.

Our results highlight the importance of the Chalk Bluff site on the Owens River because it has persistently supported a large breeding population of SWIFL, averaging 22 territories per year from 2014-2016 (Table 1). More than 50\% of all nesting SWIFL in the Owens Valley were located at the Chalk Bluff site and past surveys have repeatedly identified the area as having the most nesting birds in the region (Laymon and Williams 1994; Rourke et al. 2004). Throughout the range of SWIFL, sites with $>20$ territories are relatively rare, making up $<5 \%$ of all sites (Durst et al. 2007). The Chalk Bluff site appears to be uniquely important for SWIFL persistence in the region and supports $12 \%$ of all known nesting SWIFL in California (22/190 territories; Durst et al. 2007).

Although we documented a decline in territory number across the three largest nesting sites between 2014 and 2016, we are reluctant to call this a trend due to the limited duration of the study. Skewed sex ratios have been identified in one declining SWIFL population (Kus et al. 2017) but we did not find any evidence of this. We documented some polygynous groups $(\mathrm{N}=6)$, but the overall sex ratio was nearly equally balanced with additional single male territories $(\mathrm{N}=10)$. To reduce impacts from livestock, livestock are removed from SWIFL habitat by 15 May (LADWP 2005; USFWS 2005) and our nest timing data support that this is an appropriate timeline to protect SWIFL nest sites.

Some SWIFL territories experienced intermittent inundation throughout the nesting season as a result of LADWP's managed flow regime. In addition, beavers were active at several nesting sites and may also have played a role in inundation. Although not quantified in this study, we observed that inundation seemed associated with some potentially positive elements including increased insect prey availability, decreased predator access, reduced temperature, and increased humidity (L. Greene, CDFW, personal observation). Other studies have found positive (Moore and Ahlers 2018) and negative (Ellis et al. 2008) correlations between inundation and SWIFL nest success. LADWP's ability to manage water flow from Pleasant Valley Reservoir into the Chalk Bluff site could potentially benefit SWIFL productivity through timely inundation, and possibly even counteract likely negative consequences caused by climate change.

In the Owens Valley, the climate is predicted to become warmer, with earlier runoff, and more extreme conditions, including drought (Morelli et al. 2011). Drought has been correlated with overall reproductive failure in other SWIFL populations (Durst et al. 2008). These surveys occurred during the most recent California drought (2012-2016). During 2016, the final and driest year of drought, we observed plant stress in the form of orange fungus (Melampsora sp.) and early leaf drop of coyote willow and wild rose that increased visual exposure of some SWIFL nests later in the season. This may have impacted nest 
outcome, particularly for late season nests. This could be the beginning of increasing stress on SWIFL which were identified as the subspecies "most vulnerable to climate change" in an analysis combining projected changes in temperature and water availability with estimates of adaptability based on distribution and genetic diversity (Ruegg et al. 2018).

For years with comprehensive nest monitoring (2015 and 2016), we found high rates of BHCO nest parasitism ( $>40 \%$ ), and relatively average rates of nest success (at least one SWIFL fledged; 45\%) compared to other studies. Whitfield and Sogge (1999) compiled data from a series of short-term studies from the 1980s and 1990s across the southwest and found parasitism rates ranged from $0-66 \%$, but only three sites had parasitism rates $>40 \%$. However, more recent and longer timescale studies have tended to find lower BHCO parasitism rates. Of 3,488 nests with known outcome along the middle Rio Grande in New Mexico from 1999-2017, 14\% were parasitized (range across years 5-21\%) with 43\% nest success (range across years $25-75 \%$ ), although these results did include some small-scale short-term BHCO removals. From 1999-2006 BHCO nest parasitism rates averaged 3\% along Roosevelt Lake in New Mexico ( $\mathrm{N}=892)$, although it varied by site and year reaching as high as $43 \%$ for a few sites in 2002 , when drought conditions reduced vegetation cover (Ellis et al. 2008). Nest success varied from 57\% pre-inundation (1996-2004, $\mathrm{N}=680$ ) to $45 \%$ during inundation (2005-2006, $\mathrm{N}=212$; Ellis et al. 2008). Along the lower Colorado River in Arizona and the Virgin River in Nevada, from 2003-2007, 23\% were parasitized (range across sites $0-32 \% ; \mathrm{N}=233$ nests). High levels of BHCO nest parasitism on the Owens Valley, in combination with high nest success in non-parasitized nests $(60 \%)$ indicate this may be a particularly good candidate for $\mathrm{BHCO}$ management.

BHCO parasitism rates above $20-30 \%$ can have significant impacts on SWIFL recruitment (USFWS 2002). Our result of lower nest success in parasitized nests is similar to other studies that have found parasitized SWIFL nests tend to fail, have lower hatching and fledging success (Whitfield and Sogge 1999) and have decreased daily nest survival (Stumpf et al. 2012). BHCO can also act as nest predators, removing host eggs and nestlings (Smith 1981) and we frequently observed the presence of a BHCO egg coincided with the reduction of a WIFL egg. Although BHCO are native to the United States, they have greatly increased and expanded with European settlement, including into California (Rothstein 1994) and they are known to be both nest parasites and nest predators (Latif et al. 2012; Lowther 2020) (Thamnophis sp.. BHCO nest parasitism on SWIFL was first documented in early 1900's and nest collection data indicates it has increased steadily since then (Whitfield and Sogge 1999). BHCO nest parasitism has been documented on over 220 other open-nesting bird species, with 144 documented to have fledged a BHCO (Lowther 2020). In our study area, we documented BHCO parasitism on red-winged blackbird, blue-gray gnatcatcher, common yellowthroat, song sparrow and yellow warbler, a California species of special concern.

Despite a clear relationship between BHCO nest parasitism and reduced host nest survival, BHCO removals have had variable impacts. In New Mexico, localized BHCO removal decreased nest parasitism rates but had no impact on overall nest success rates (Moore and Ahlers 2018). In Arizona and Nevada, BHCO parasitism reduced individual nest success and the seasonal productivity of individuals, but longer term data analyses indicated it may not reduce the overall lifetime reproductive success of individuals, as individuals compensate by renesting and increasing egg production (Stumpf 2011). Although BHCO management has had variable results (USFWS 2002; Schofield et al. 2021), BHCO removal has been successful in the nearby Amargosa River drainage where BHCO trapping has essentially eliminated BHCO from the system and host productivity (fledglings/ 
brood attempt) has nearly tripled (McCreedy 2020). BHCO numbers may also be reduced more passively by reducing food availability at brood sites (e.g., switching to pellet feed at stables and corrals; Schofield et al. 2021). Additionally, lower levels of parasitism has been documented in taller trees (Brodhead et al. 2007), inundated habitat (Moore and Ahlers 2018), smaller habitat patches (Brodhead et al. 2007), and in habitat farther from the edge (Stumpf et al. 2012). These studies indicate that habitat management may be an effective way to reduce nest parasitism.

\section{Recommendations}

We recommend continued nest monitoring of known SWIFL nest sites to determine if $\mathrm{BHCO}$ parasitism rates remain high outside of drought conditions. Further nest fate analyses should be conducted to identify the relative importance of nest predation and nest parasitism as well as habitat features that may help to mitigate these factors. At the Chalk Bluffs site, we consistently observed BHCO perched on snags within SWIFL nest areas and distance from snag might also be a factor driving parasitism rates. Additionally, the feasibility of BHCO management should be evaluated; banding BHCO present within SWIFL nest sites would be a first step in identifying BHCO roost sites that could be targets for passive or active management (Schofield et al., 2021). Further demographic and nest habitat analyses should be conducted to determine the impact of climatic and hydrologic conditions, livestock grazing, as well as fire (e.g., 2018 Pleasant fire) and non-native plants (e.g., Tamarisk sp.) on breeding SWIFL.

Funding for this work was provided by USFWS Section 6 Grant F13AP00745 and CDFW 2015 Drought Funding, with additional staff support from LADWP, USFWS, PBCS and the Bishop Paiute Tribe. We thank one anonymous reviewer, as well as Mary Clapp and Helen Loffland, who contributed significantly to improving and clarifying this manuscript with their thoughtful and comprehensive reviews.

\section{LITERATURE CITED}

Brodhead, K. M., S. H. Stoleson, and D. M. Finch. 2007. Southwestern willow flycatchers (Empidonax trailii extimus) in a grazed landscape: factors influencing brood parasitism. The Auk 124:1213-1228.

Durst, S. L., M. K. Sogge, S. D. Stump, S. O. Williams, B. E. Kus, and J. Susan. 2007. Southwestern Willow Flycatcher Breeding Site and Territory Summary - 2006: USGS Open File Report 2007-1931. U.S. Geological Survey, Southwest Biological Science Center, Colorado Plateau Research Station, Flagstaff, AZ, USA.

Durst, S. L., T. C. Theimer, E. H. Paxton, and M. K. Sogge. 2008. Age, habitat, and yearly variation in the diet of a generalist insectivore, the Southwestern willow flycatcher. Condor 110:514-525.

Ellis, L. A., S. D. Stump, and D. M. Weddle. 2008. Southwestern willow flycatcher population and habitat response to reservoir inundation. Journal of Wildlife Management 73:946-954.

Grinnell, J., and A. H. Miller. 1944. The Distribution of Birds of California. Cooper Ornithological Club, Berkeley, CA, USA.

Kus, B. E., S. L. Howell, and D. A. Wood. 2017. Female-biased sex ratio, polygyny, and persistence in the endangered Southwestern Willow Flycatcher (Empidonax traillii extimus). Condor 119:17-25. 
Latif, Q. S., S. K. Heath, and G. Ballard. 2012. The nest predator assemblage for songbirds in Mono Lake basin riparian habitats. Western North American Naturalist 72:276-287.

Laue, A. 2017. Hiding in Plain Sight. The Medium. Available from: https://medium.com/ invironment/hiding-in-plain-sight-dc15e99df8be

Laymon, S. A., and P. L. P. L. Williams. 1994. Riparian and wetland breeding bird surveys, Inyo county, California, with emphasis on the yellow-billed cuckoo and the snowy plover. CDFW Final Report, Sacramento, CA, USA.

Loffland, H., R. Siegel, R. Burnett, Ch. Stermer, and T. Mark. 2014. Assessing willow flycatcher population size and distribution to inform meadow restoration priorities in the Sierra Nevada and Southern Cascades. The Institute for Bird Populations, Point Reyes Station, CA, USA.

Los Angeles Department of Water and Power (LADWP). 2005. Conservation Strategy for the Southwestern Willow Flycatcher on City of Los Angeles Department of Water and Power Lands in the Owens Management Unit. Available from: https:// inyo-monowater.org/wp-content/uploads/2011/09/LADWP-willow-flycatcherconservation-strategy.pdf

Lowther, P. E. 2020. Brown-headed Cowbird (Molothrus ater), version 1.0. A. F. Poole and F. B. Gill, editors. Birds of the World. Cornell Lab of Ornithology, Ithaca, NY, USA.

Martin, T. E., and G. R. Geupel. 1993. Nest-monitoring plots: methods for locating nests and monitoring success. Journal of Field Ornithology 64:507-519.

McCreedy, C. 2020. Amargosa canyon songbird project 2019 progress report. Point Blue Contribution No. 2274.

McCreedy, C., and S. K. Heath. 2004. Atypical willow flycatcher nesting sites in a recovering riparian corridor at Mono Lake, California. Western Birds 35:197-209.

Moore, D., and D. Ahlers. 2018. Middle Rio Grande southwestern willow flycatcher study results - selected sites along the Rio Grande from Bandelier National Monument to Elephant Butte reservoir, New Mexico. U.S. Bureau of Reclamation, Fisheries and Wildlife Resources, Denver, CO, USA.

Morelli, T. L., M. C. McGlinchy, and R. P. Neilson. 2011. A climate change primer for land managers: an example from the Sierra Nevada. Res. Pap. PSW-RP-262. U.S. Forest Service, Pacific Southwest Research Station, Albany, CA. USA.

Paxton, E. H., and J. C. Owen. 2002. An aging guide for willow flycatcher nestlings. Northern Arizona University, Colorado Plateau Field Station, Flagstaff, AZ, USA.

Rothstein, S. I. 1994. The cowbirds's invasion of the far west: history, causes and consequences experienced by host species. Studies in Avian biology 15:301-315.

Rourke, J. W., B. E. Kus, and M. J. Whitfield. 2004. Distribution and abundance of the southwestern willow flycatcher at selected southern California sites in 2001. California Department of Fish and Game, Wildlife Management Division, Species Conservation and Recovery Program Report 2004-05.

Ruegg, K., R. A. Bay, E. C. Anderson, J. F. Saracco, R. J. Harrigan, M. Whitfield, E. H. Paxton, and T. B. Smith. 2018. Ecological genomics predicts climate vulnerability in an endangered southwestern songbird. Ecology Letters 21:1085-1096.

Schofield, L. N., H. L. Loffland, R. B. Siegel, T. Mark, and C. Stermer. 2021. A Conservation Strategy for Willow Flycatcher (Empidonax traillii) in California. Institute for Bird Populations, Petaluma, CA, USA. 
Siegel, R. B., R. L. Wilkerson, and D. F. D. Sante. 2008. Extirpation of the Willow Flycatcher from Yosemite National Park. Western Birds 39:8-21.

Smith, J. N. M. 1981. Cowbird parasitism, host fitness, and age of the host female in an island song sparrow population. Condor 83:152-161.

Sogge, M. K., and S. J. Sferra. 2010. A natural history summary and survey protocol for the Southwestern Willow Flycatcher. U.S. Geological Survey Techniques and Methods 2A-10.

Stumpf, K. J. 2011. Factors affecting population growth and genetic structuring of southwestern willow flycatchers. Dissertation, Northern Arizona University, Flagstaff, AZ, USA.

Stumpf, K. J., N. College, and E. Avenue. 2012. Distance from riparian edge reduces brood parasitism of southwestern willow flycatchers, whereas parasitism increases nest predation risk. Journal of Wildlife Management 76:269-277.

Theimer, T. C., A. D. Smith, S. M. Mahoney, and K. E. Ironside. 2016. Available data support protection of the Southwestern Willow Flycatcher under the Endangered Species Act. The Condor 118:289-299.

Unitt, P. 1987. Empidonax trailii extimus: an endangered subspecies. Western Birds 18:146-152.

U.S. Fish and Wildlife Service (USFWS). 2002. Final Recovery Plan Southwestern Willow Flycatcher (Empidonax traillii extimus). Region 2, Albuquerque, NM, USA.

U.S. Fish and Wildlife Service (USFWS). 2005. Memorandum of Understanding between USFWS Ventura Field Office and Los Angeles Department of Water and Power.

U.S. Fish and Wildlife Service (USFWS). 2013. Designation of critical habitat for southwestern willow flycatcher. Federal Register 78:343-534.

U.S. Fish and Wildlife Service (USFWS) 2017. Southwestern willow flycatcher 5-Year review: summary and evaluation. Arizona Ecological Services, Phoenix, AZ, USA.

Whitfield, M. J., and M. K. Sogge. 1999. Range-wide impact of Brown-headed Cowbird parasitism on the southwestern willow flycatcher (Empidonax traillii extimus). Studies in Avian Biology 18:182-190.

Submitted 28 October 2020

Accepted 1 January 2021

Associate Editor was M. Wieland 